\title{
Smallanthus sonchifolius (Poepp.) H. Rob. (yacón): identificação microscópica de folha e caule para o controle de qualidade farmacognóstico
}

\author{
Márcia do Rocio Duarte*, Samantha Wolf, Bruna Gruskoski de Paula
}

Laboratório de Farmacognosia, Departamento de Farmácia, Universidade Federal do Paraná

* Correspondência

M. R. Duarte

Departamento de Farmácia

Universidade Federal do Paraná

Av. Pref. Lothário Meissner, 632, Jardim Botânico

80210-170 - Curitiba - PR, Brasil E-mail: marciard@ufpr.br
Yacón é a denominação popular da erva perene nativa dos Andes, Smallanthus sonchifolius (Poepp.) H. Rob. (Asteraceae), cultivada em diferentes países como recurso alimentar e medicinal. Raizes tuberosas e partes vegetativas aéreas são freqüentemente empregadas como coadjuvante no tratamento do diabetes. Este trabalho objetivou estudar os caracteres anatômicos de folha e caule, a fim de fornecer informações para a identificação microscópica no controle de qualidade farmacognóstico. O material botânico foi fixado e preparado de acordo com técnicas usuais de microscopia de luz e eletrônica de varredura. A folha é anfiestomática, com predominância de estômatos anomocíticos. Tricomas tectores e glandulares estão presentes, sendo os primeiros pluricelulares e unisseriados. Os tricomas glandulares são curtos e pluricelulares, com duas séries de células. O mesofilo é dorsiventral e a nervura central possui vários feixes vasculares colaterais em disposição cêntrica. O caule jovem apresenta epiderme persistente, colênquima angular, parênquima cortical, endoderme e cilindros contínuos de floema e xilema. Dutos secretores encontram-se na folha e no caule. O conjunto dos caracteres observados, como a presença de tricomas tectores e glandulares, dutos secretores e endoderme com estrias de Caspary, é útil para o controle de qualidade dessa espécie.
Unitermos

- Farmacobotânica

- Smallanthus sonchifolius/ Diagnose microscópica

- Tricoma

- Yacón

\section{INTRODUÇÃO}

Smallanthus sonchifolius (Poepp.) H. Rob. (Figuras $1 \mathrm{a} 4)$ pertence à família Asteraceae (Compositae) e, freqüentemente, é referido pelo basiônimo Polymnia sonchifolia Poepp. Conhecido popularmente como yacón, é uma planta perene nativa dos Andes e cultivada em dife- rentes países, desde Colômbia até nordeste da Argentina, Brasil, República Checa, Nova Zelândia e Japão (Inoue et al., 1995; Yan et al., 1999; Kortsarz, Grau, 2000; Graefe et al., 2004).

A planta possui porte herbáceo, podendo atingir 2-3 m de altura (Aybar et al., 2001; Graefe et al., 2004). Apresenta raízes tuberosas, caules cilíndricos e fistulosos na 
maturidade, folhas opostas cruzadas, simples, ovadas a ovado-lanceoladas, de ápice acuminado, base truncada a sagitada e margem denteado-serrilhada, e inflorescências terminais de cor amarela (Kortsarz, Grau, 2000; Aybar et al., 2001; Mercado et al., 2006).

Os órgãos vegetativos são utilizados como recurso alimentar e medicinal. As raízes são suculentas, destituídas de amido e ricas em oligofrutanas que, por não serem metabolizadas no trato digestivo, têm um valor energético relativamente baixo, apesar do sabor adocicado (Aybar et al., 2001; Graefe et al., 2004; Fernández et al., 2006). Por essa razão, o consumo de raízes de yacón não aumenta os níveis de glucose sanguínea, sendo indicado para indivíduos diabéticos, com sobrepeso ou obesos (Fernández et al., 2006). Folhas e caules apresentam compostos fenólicos e forte atividade antioxidante, e são considerados suplemento alimentar em potencial na prevenção de doenças crônicas envolvendo estresse oxidativo, particularmente diabetes do tipo II (Valentová et al., 2004; 2005; Terada et al., 2006) e arteriosclerose (Valentová et al., 2003). Na medicina popular, as folhas são dessecadas e preparadas na forma de chá como coadjuvante no tratamento do diabetes (Aybar et al., 2001), no controle da pressão arterial e na redução dos níveis de colesterol (Vignale, Gurni, 2005).

Diante do uso crescente do yacón e do interesse científico que vem despertando, este trabalho objetivou estudar os caracteres anatômicos de folha e caule de S. sonchifolius, a fim de fornecer informações para a identificação microscópica no controle de qualidade farmacognóstico e, adicionalmente, na análise de alimentos.

\section{MATERIAL E MÉTODOS}

Amostras de S. sonchifolius foram coletadas de exemplares cultivados em Curitiba, PR, nas coordenadas aproximadas de $25^{\circ} 26^{\prime} \mathrm{S}$ e $49^{\circ} 14^{\prime}$ ' W e altitude de $930 \mathrm{~m}$, em agosto de 2004. O material florido foi identificado por taxonomista e confere com a exsicata MBM 76424 do Herbário do Museu Botânico Municipal de Curitiba.

Folhas adultas e caules jovens foram fixados em FAA 70 (Johansen, 1940) e posteriormente armazenados em etanol a $70 \%$ (Berlyn, Miksche, 1976). Analisaram-se o terço inferior do limbo, de folhas do quarto ao sexto nós, e fragmentos de caules, obtidos entre $5-15 \mathrm{~cm}$ do ápice caulinar. Para o preparo de lâminas semipermanentes, o material vegetal foi seccionado nos sentidos paradérmico, transversal e longitudinal, à mão livre, e corado com azul de toluidina (O'Brien et al., 1964). Utilizou-se a técnica de inclusão em glicolmetacrilato (Feder, O'Brien, 1968) para a confecção de lâminas permanentes, a partir de seccionamento transversal em micrótomo rotatório e dupla coloração com azul de astra e fucsina básica (Brito, Alquini, 1996).

Testes microquímicos comuns foram realizados com lugol para a identificação de amido (Berlyn, Miksche, 1976), $\mathrm{FeCl}_{3}$ para compostos fenólicos (Johansen, 1940), Sudam III para substâncias lipofílicas (Sass, 1951) e floroglucina clorídrica para elementos lignificados (Foster, 1949).

$\mathrm{Na}$ análise ultra-estrutural da superfície foliar (Souza, 1998), fragmentos de folhas fixadas foram desidratados inicialmente em uma série etanólica crescente e posteriormente pelo ponto crítico de $\mathrm{CO}_{2}$ no equipamento Bal-Tec CPD-030. Esse material foi aderido a suporte e metalizado com ouro no aparelho Balzers Sputtering SCD-030, para ser examinado em alto vácuo no microscópio eletrônico de varredura Jeol JSM-6360 LV.

\section{RESULTADOS}

\section{Folha}

As células epidérmicas, em vista frontal, apresentam paredes anticlinais delgadas e sinuosas (Figuras 5 e 6), e são revestidas por uma cutícula lisa (Figuras 12 e 13). Estômatos predominantemente anomocíticos encontram-se em maior número na face abaxial (Figura 6) e são raros na superfície adaxial, sendo a folha anfiestomática. Em secção transversal, as células-guarda inserem-se levemente acima das células adjacentes (Figura 15). Tricomas tectores e glandulares (Figuras 12 e 13) estão presentes em ambas as superfícies foliares. Os primeiros são eretos, pluricelulares (duas a dez células), unisseriados, exibindo célula apical relativamente alongada e de extremidade afilada (Figuras 7 e 8). Os tricomas glandulares são curtos, pluricelulares, com duas séries de células, podendo apresentar a cutícula distendida (Figuras 9 a 11).

A epiderme é uniestratificada e o mesofilo é dorsiventral, consistindo de cerca de duas camadas de parênquima paliçádico e seis de esponjoso, o qual representa $70 \%$ da espessura do clorênquima (Figura 15). Feixes vasculares colaterais, de pequeno porte, percorrem o mesofilo e são circundados por bainha parenquimática (Figura 15).

A nervura central, em secção transversal, exibe contorno nitidamente biconvexo (Figura 14). A epiderme possui um único estrato e, subjacente, encontram-se cerca de seis camadas de colênquima angular junto à face adaxial e de três na superfície oposta. Em meio a células parenquimáticas, distribuem-se vários feixes vasculares colaterais (Figura 16) em disposição aproximadamente cêntrica (Figura 14). Ao redor dos feixes de maior porte, observa-se bainha amilífera (Figura 17). Dutos secretores, 

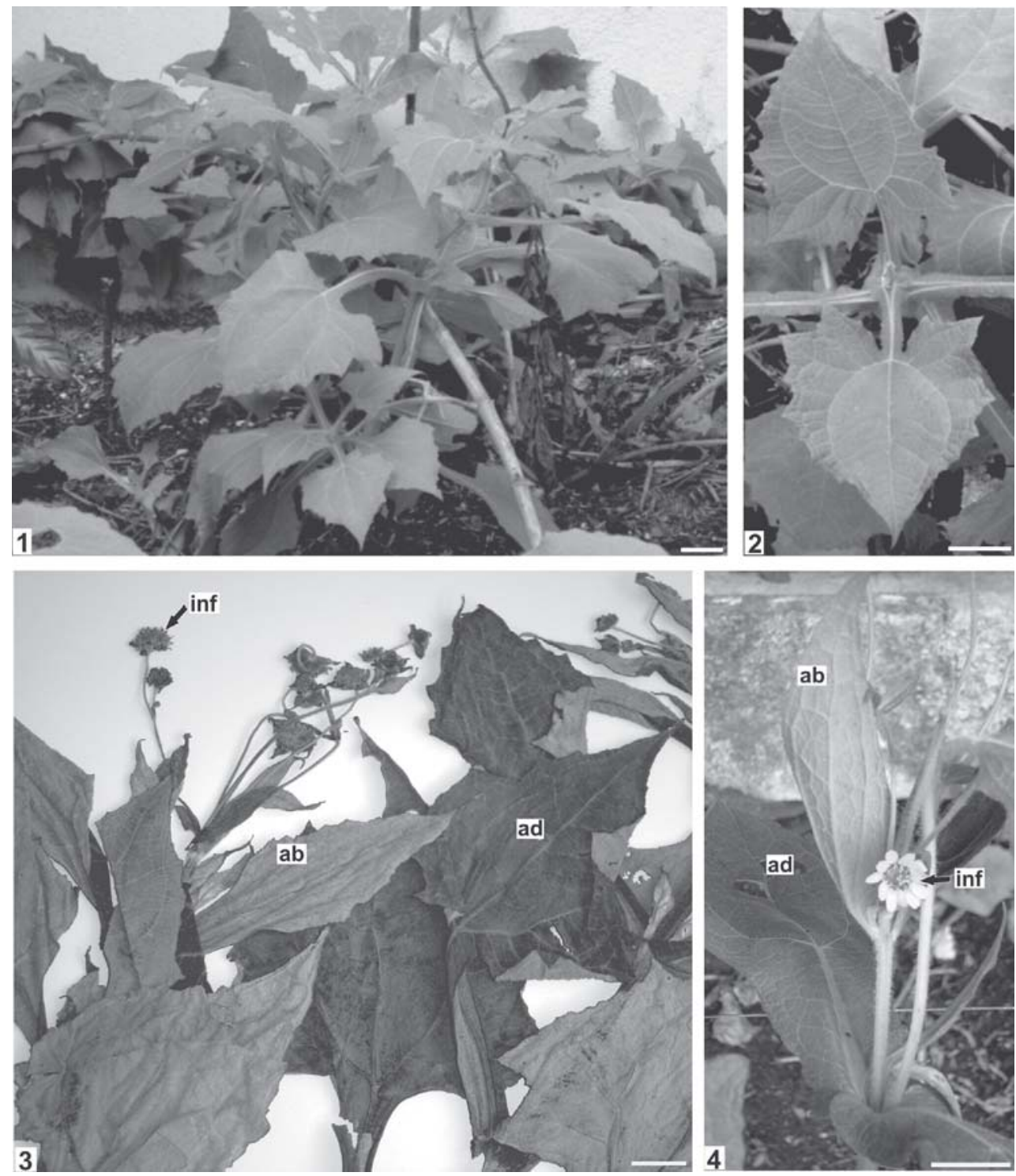

FIGURAS 1-4 - Smallanthus sonchifolius (Poepp.) H. Rob.: 1. Aspecto geral no hábito; 2. Detalhe das folhas; 3. Material herborizado; 4. Pormenor de um ramo florido. ab - face abaxial da folha, ad - face adaxial da folha, inf - inflorescência. Barra $=2 \mathrm{~cm}$.

de epitélio uniestratificado, citoplasma denso e núcleo evidente, que armazenam substâncias lipofílicas, estão localizados no parênquima, freqüentemente nas proximidades dos feixes vasculares (Figura 17). Essas estruturas secretoras internas também são encontradas acompanhando feixes vasculares de médio porte na lâmina foliar.

\section{Caule}

A epiderme caulinar persiste (Figuras 18, 19 e 21), apresentando um único estrato de células e tricomas semelhantes aos da folha. No córtex, há uma faixa contínua de colênquima angular e várias camadas de parênquima (Fi- guras 19 e 21), ambos contendo poucos cloroplastos, e uma endoderme (Figuras 19 e 20), com estrias de Caspary. Dutos secretores (Figuras 19 a 21), de epitélio uniestratificado, ocorrem na região cortical e na medula. No cilindro vascular, é possível distinguir diversos feixes vasculares colaterais (Figuras 18 a 20), embora floema e xilema secundários sejam contínuos em toda a circunferência do caule. Calotas de esclerênquima apõem-se ao floema, que é formado de elementos crivados e células parenquimáticas (Figuras 19 e 20). No xilema, encontramse elementos traqueais, fibras e células parenquimáticas (Figura 19). A medula é parenquimática (Figuras 18 e 19) e representa grande parte do volume caulinar. 

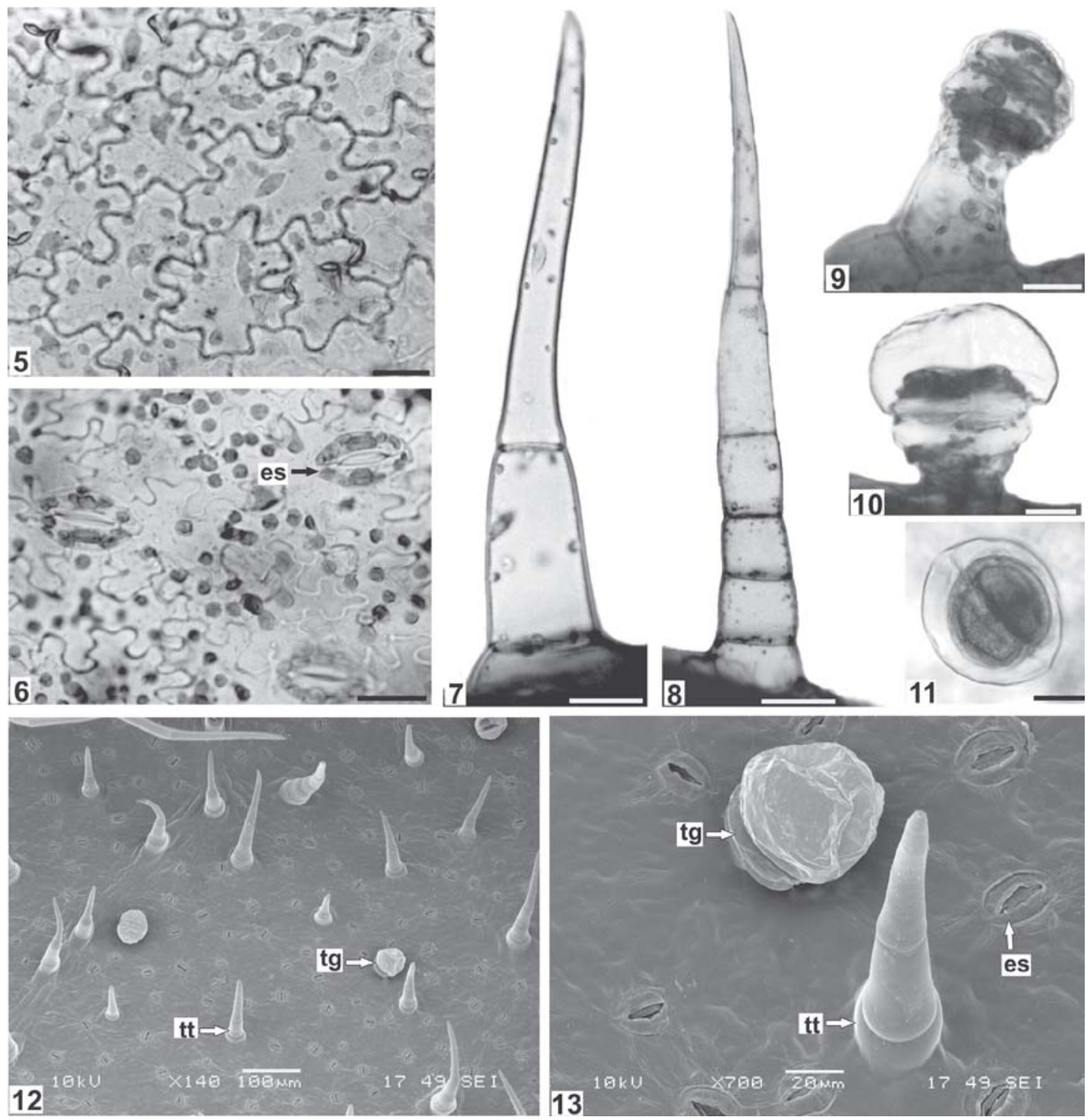

FIGURAS 5-13 - Smallanthus sonchifolius (Poepp.) H. Rob. - folha: 5, 6. Vista frontal, faces adaxial e abaxial da epiderme, respectivamente; 7, 8. Tricomas tectores; 9-11. Tricomas glandulares; 12, 13. Vista frontal da face abaxial da epiderme, em microscopia eletrônica de varredura. es - estômato, $\mathrm{tg}$ - tricoma glandular, $\mathrm{tt}$ - tricoma tector. Barra $=20 \mu \mathrm{m}$.

\section{DISCUSSÃO}

Levando-se em conta os aspectos anatômicos observados neste estudo, $S$. sonchifolius segue o padrão para Asteraceae (Metcalfe, Chalk, 1950), ao apresentar estômatos anomocíticos, mesofilo dorsiventral e feixes vasculares colaterais na folha, bem como epiderme persistente, calotas esclerenquimáticas apostas ao floema e feixes vasculares colaterais dispostos em círculo único no caule. Na opinião de Metcalfe e Chalk (1950), determinados caracteres possuem considerável valor taxonômico, merecendo destaque a presença de diferentes tipos de tricomas, dutos secretores e endoderme definida no caule.
Os tricomas tectores observados neste trabalho correspondem em geral à descrição de Vignale e Gurni (2005) e Mercado et al. (2006) para esses anexos epidérmicos em yacón e são similares aos mencionados em outras plantas medicinais da família, a exemplo de Bidens pilosa L. (Duarte, Estelita, 1999; Ferreira et al., 2002), Ageratum conyzoides L., Emilia sonchifolia (L.) DC. (Ferreira et al., 2002), Mikania cordifolia (L. f.) Willd. (Oliveira et al., 2000) e Calea uniflora Less. (Budel et al., 2006).

Com relação aos tricomas glandulares, o tipo pluricelular e bisseriado é considerado freqüente na família (Metcalfe, Chalk, 1950), tendo sido relatado em diver- 


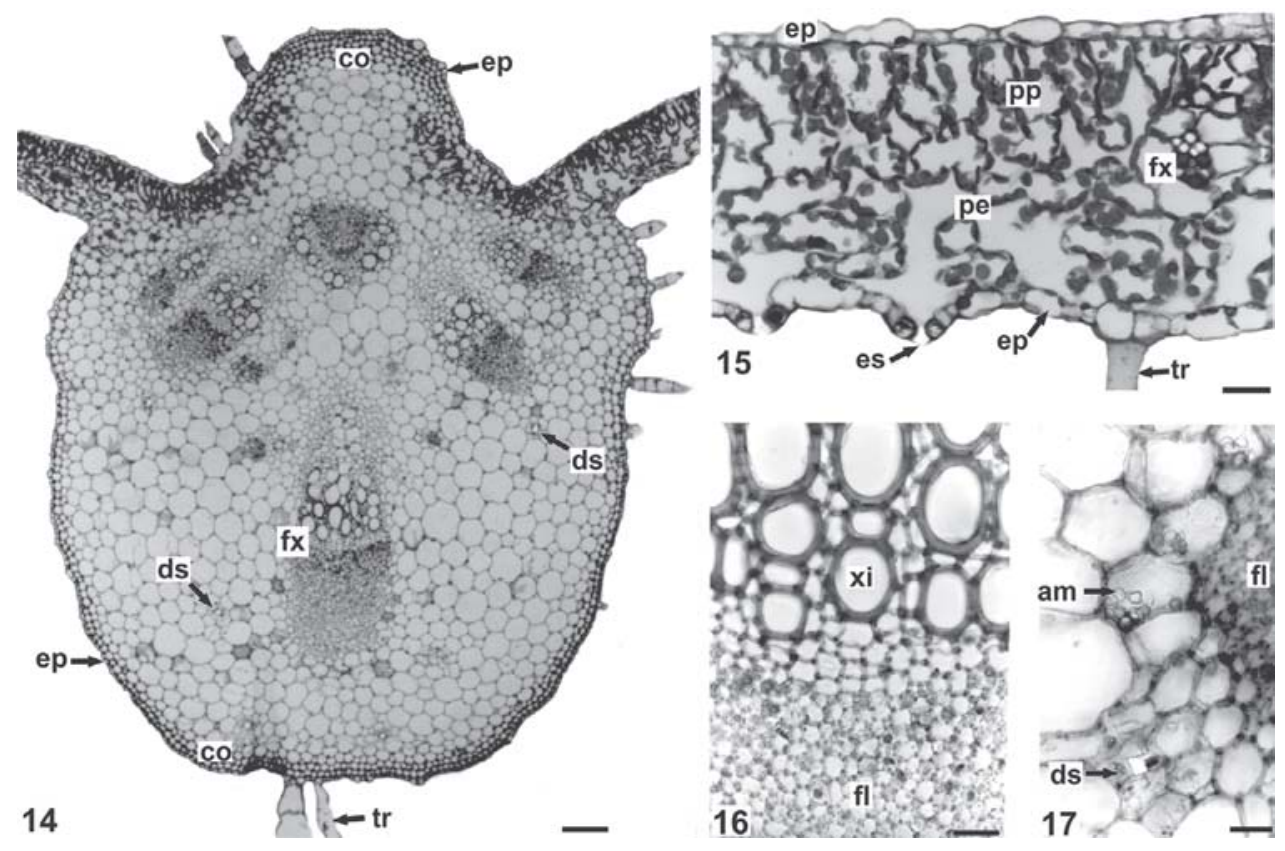

FIGURAS 14-17 - Smallanthus sonchifolius (Poepp.) H. Rob. - folha, em secção transversal: 14. Nervura central e parte da região internervural; 15. Detalhe da região internervural, destacando o mesofilo; 16. Pormenor de um feixe vascular colateral da nervura central; 17 . Duto secretor nas proximidades de um feixe vascular na nervura central. am - amiloplasto, co - colênquima, ds - duto secretor, ep - epiderme, es - estômato, fl - floema, fx - feixe vascular, pe - parênquima esponjoso, pp - parênquima paliçádico, tr - tricoma, xi - xilema. Barra $=100 \mu \mathrm{m}$ (14), $20 \mu \mathrm{m}(15-17)$.

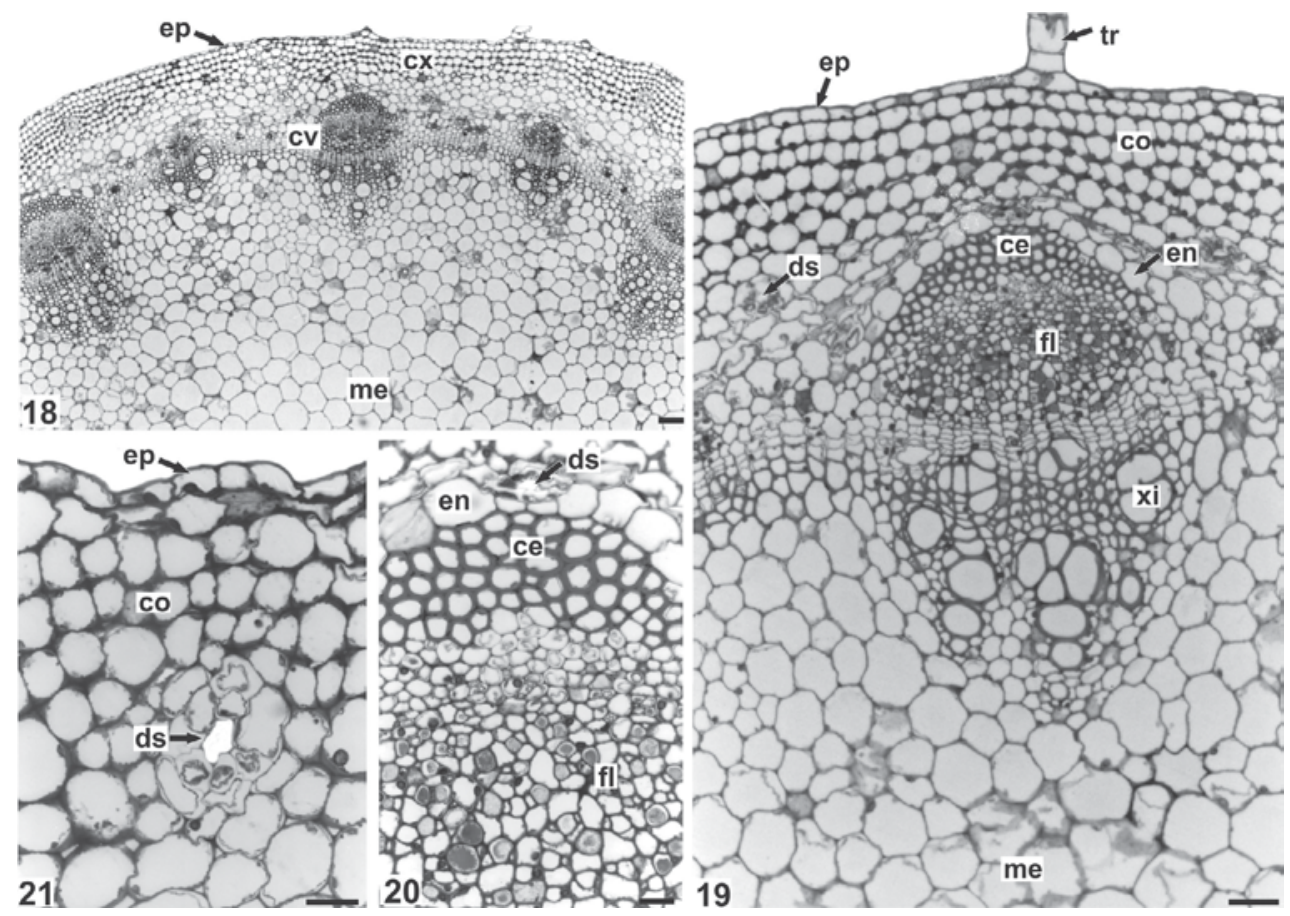

FIGURAS 18-21 - Smallanthus sonchifolius (Poepp.) H. Rob. - caule, em secção transversal: 18. Organização caulinar geral; 19. Epiderme, córtex e cilindro vascular; 20. Detalhe da endoderme e de uma calota esclerenquimática aposta ao floema; 21. Pormenor do colênquima angular e de um duto secretor. ce - calota esclerenquimática, co - colênquima, cv - cilindro vascular, cx - córtex, ds - duto secretor, en - endoderme, ep - epiderme, fl-floema, me - medula, tr - tricoma, xi - xilema. Barra $=100 \mu \mathrm{m}(18), 50 \mu \mathrm{m}(19), 20 \mu \mathrm{m}(20,21)$. 
sas espécies medicinais, como Artemisia nitida Bertol. (Corsi, Nencioni, 1995), A. nova A. Nelson (Kelsey, Shafizadeh, 1980), Santolina leucantha Bertol. (Pagni, Masini, 1999), Stevia rebaudiana (Bert.) Bert. (Monteiro et al., 2001), Tanacetum parthenium (L.) Sch. Bip. (Simmons et al., 2002), C. uniflora (Budel et al., 2006) e M. cordifolia (Oliveira et al., 2000). De modo semelhante, esse tipo foi descrito em folha de $S$. sonchifolius por Vignale e Gurni (2005) e Mercado et al. (2006).

Em se tratando de dutos secretores, essas estruturas internas de secreção estão presentes em várias espécies medicinais de Asteraceae, tais como B. pilosa (Duarte, Estelita, 1999), Mikania malacolepis B.L. Rob. (Rodrigues et al., 1996), M. glomerata Spreng. (Neves, Sá, 1991), Baccharis cylindrica (Less.) DC. (Budel et al., 2004) e C. uniflora (Budel et al., 2006). De acordo com Oliveira et al. (2000), em M. cordifolia os dutos secretores estão associados a feixes vasculares e são do tipo esquizógeno.

Descrição semelhante à desta investigação para dutos secretores foi apresentada por Mercado et al. (2006) ao estudarem alguns aspectos foliares de S. sonchifolius. Esses autores concluíram que a formação dessas estruturas segue o padrão esquizógeno, embora não tenham feito referência à realização de estudos ontogenéticos. No trabalho de Vignale e Gurni (2005) não há menção a dutos secretores em yacón.

Considerando-se os metabólitos secundários produzidos pelas estruturas de secreção, análises histoquímicas demonstraram que as secreções de tricomas glandulares e dutos secretores, embora semelhantes, não são idênticas (Corsi, Nencioni, 1995; Pagni, Masini, 1999). Em $S$. leucantha o produto secretado pelos tricomas glandulares consiste de lactonas sesquiterpênicas, terpenóides, alcalóides, lipídios, taninos e substâncias pécticas. Entretanto, os dois últimos grupos de compostos não foram detectados no conteúdo dos dutos secretores (Pagni, Masini, 1999). Em A. nitida, o produto secretado pelos tricomas glandulares inclui também polissacarídeos, os quais estavam ausentes da secreção interna (Corsi, Nencioni, 1995). Na espécie $S$. sonchifolius, Schorr e Costa (2003) avaliaram apenas os principais produtos dos tricomas glandulares, classificando-os como lactonas sesquiterpênicas, identificadas como enidrina e uvedalina, que segundo esses pesquisadores podem ser utilizadas como marcadores químicos do yacón.

$\mathrm{Na}$ família Asteraceae, a endoderme que constitui o limite interno do córtex pode apresentar uma fita de suberina, que é denominada de estria de Caspary e caracteriza a endoderme típica, ou conter amido, sendo referida como bainha amilífera (Metcalfe, Chalk, 1950). A endoderme é encontrada em caules aéreos de algumas herbáceas e rizomas (Fahn, 1990), e possui caráter diagnóstico relevante já que é menos comum em caule do que raiz (Mauseth, 1988). Na espécie em questão, endoderme típica é evidenciada no eixo caulinar, da mesma forma que foi referida em algumas espécies medicinais, como em $B$. pilosa (Duarte, Estelita, 1999), M. cordifolia (Oliveira et al., 2000) e M. glomerata (Neves, Sá, 1991).

É importante ressaltar, finalmente, que o conjunto de caracteres estruturais registrados em $S$. sonchifolius, como os tipos de tricomas tector e glandular, a presença de dutos secretores em folha e caule, e a ocorrência de endoderme com estrias de Caspary no eixo caulinar, pode ser utilizado na identificação dessa espécie, evitando-se confusão com outras espécies de Asteraceae de interesse medicinal.

\section{AGRADECIMENTOS}

Ao CNPq pela bolsa concedida à segunda autora, ao CME-UFPR pelas análises de MEV, à Profa. Nilce Nazareno da Fonte pela coleta do material botânico, ao Prof. Antônio Dunaiski e aos taxonomistas do MBMCuritiba pela identificação da espécie.

\section{ABSTRACT}

\section{Smallanthus sonchifolius (Poepp.) H. Rob. (yacon): microscopical identification of the leaf and stem for the pharmacognostic quality control}

Yacon is the common name of the perennial herb native to the Andes, Smallanthus sonchifolius (Poepp.) H. Rob. (Asteraceae), cultivated in different countries as food and medicinal resource. Fleshy roots and aerial vegetative organs are often used in the treatment of diabetes. This work has aimed to study the anatomical characters of the leaf and stem, aiming to supply information for microscopic identification of the pharmacognostic quality control. The botanical material was fixed and prepared according to standard techniques of light and scanning electron microscopy. The leaf is amphistomatic, predominantly with anomocytic stomata. Non-glandular and glandular trichomes are present, being the former multicellular and uniseriate. The glandular ones are short and multicellular, with two series of cells. The mesophyll is dorsiventral and the midrib has various collateral vascular bundles in centric arrangement. The young stem has remaining epidermis, angular collenchyma, cortical parenchyma, endodermis and continuous cylinders of phloem and xylem. Secretory ducts are found in the leaf and stem. The assembled characters, such as non-glandu- 
lar and glandular trichomes as well as secretory ducts and endodermis with Casparian strips, are useful for the quality control of this species.

UNITERMS: Pharmacobothanic. Smallanthus sonchifolius/Microscopic diagnosis. Trichome. Yacon.

\section{REFERÊNCIAS BIBLIOGRÁFICAS}

AYBAR, M. J.; SÁNCHEZ-RIERA, A. N.; GRAU, A.; SÁNCHEZ, S. S. Hypoglycemic effect of the water extract of Smallantus sonchifolius (yacon) leaves in normal and diabetic rats. J. Ethnopharmacol., v. 74, p. 125-132, 2001.

BERLYN, G. P.; MIKSCHE, J. P. Botanical microtechnique and cytochemistry. Ames: Iowa State University Press, 1976. $326 \mathrm{p}$.

BRITO, J. F. A.; ALQUINI, Y. A new method for staining botanical material embedded in glycol methacrylate (GMA). Braz. Arch. Biol. Technol., v. 39, p. 949-951, 1996.

BUDEL, J. M.; DUARTE, M. R.; PAULO, V. F.; TAKEDA, I. J. M. Caracteres anatômicos de folha e caule de Calea uniflora Less., Asteraceae. Braz. J. Pharmacogn., v. 16, p. 53-60, 2006.

BUDEL, J. M.; DUARTE, M. R.; SANTOS, C. A. M. Stem morpho-anatomy of Baccharis cylindrica (Less.) DC. (Asteraceae). Braz. J. Pharm. Sci., v. 40, p. 93-99, 2004.

CORSI, G.; NENCIONI, S. Secretory structures in Artemisia nitida Bertol. (Asteraceae). Israel J. Plant Sci., v. 43, p. 359-365, 1995.

DUARTE, M. R.; ESTELITA, M. E. Caracteres anatômicos de Bidens pilosa L., Asteraceae. Hoehnea, v. 26, p. 15-27, 1999.

FAHN, A. Plant anatomy. 4. ed. Oxford: Pergamon Press, 1990. $588 \mathrm{p}$.

FEDER, N.; O'BRIEN, T. P. Plant microtechnique: some principles and new methods. Am. J. Bot., v. 55, p. 123142, 1968.
FERNÁNDEZ, E. C.; VIEHMANNOVÁ, I.; LACHMAN, J.; MILELLA, L. Yacon [Smallanthus sonchifolius (Poeppig \& Endlicher) H. Robinson]: a new crop in the Central Europe. Plant Soil Environ., v. 52, p. 564-570, 2006.

FERREIRA, E. A.; PROCÓPIO, S. O.; SILVA, E. A. M.; SILVA, A. A.; RUFINO, R. J. N. Estudos anatômicos de folhas de espécies de plantas daninhas. II. Bidens pilosa, Emilia sonchifolia, Ageratum conyzoides e Sonchus asper. Planta Dan., v. 20, p. 327-335, 2002.

FOSTER, A. S. Practical plant anatomy. 2. ed. New York: D. Van Nostrand, 1949. 228 p.

GRAEFE, S.; HERMANN, M.; MANRIQUE, I.; GOLOMBEK, S.; BUERKERT, A. Effects of postharvest treatments on the carbohydrate composition of yacon roots in the Peruvian Andes. Field Crops Res., v. 86, p. 157-165, 2004.

INOUE, A.; TAMOGAMI, S.; KATO, H.; NAKAZATO, Y.; AKIYAMA, M.; KODAMA, O.; AKATSUKA, T.; HASHIDOKO, Y. Antifungal melampolides from leaf extracts of Smallanthus sonchifolius. Phytochemistry, v. 39, p. 845-848, 1995.

JOHANSEN, D. A. Plant microtechnique. New York: McGraw-Hill Book, 1940. 523 p.

KELSEY, R. G.; SHAFIZADEH, F. Glandular trichomes and sesquiterpene lactones of Artemisia nova (Asteraceae). Biochem. Syst. Ecol., v. 8, p. 371-377, 1980.

KORTSARZ, A.; GRAU, A. Yacón: monografia. Fitocien. Rev., v. 3, p. 21-24, 2000.

MAUSETH, J. D. Plant anatomy. Menlo Park: Benjamin/ Cummings, $1988.560 \mathrm{p}$.

MERCADO, M. I.; PONESSA, G. I.; GRAU, A. Morfología y anatomía foliar de "yacón", Smallanthus sonchifolius (Asteraceae), con fines de control de calidad. Acta Farm. Bonaerense, v. 25, p. 526-532, 2006.

MetCAlfe, C. R.; CHALK, L. Anatomy of the dicotyledons: leaves, stem, and wood in relation to taxonomy, with notes on economic uses. Oxford: Clarendon Press, 1950. v. 2, 1500 p. 
MONTEIRO, W. R.; CASTRO, M. M.; MAZZONIVIVEIROS, S. C.; MAHLBERG, P. G. Development and some histochemical aspects of foliar glandular trichomes of Stevia rebaudiana (Bert.) Bert. - Asteraceae. Rev. Bras. Bot., v. 24, p. 349-357, 2001.

NEVES, L. J.; SÁ, M. F. A. Contribuição ao estudo das plantas medicinais - Mikania glomerata Spreng. Rev. Bras. Farm., v. 72, p. 42-47, 1991.

O'BRIEN, T. P.; FEDER, N.; MCCULLY, M. E. Polychromatic staining of plant cell walls by toluidine blue O. Protoplasma, v. 59, p. 368-373, 1964.

OLIVEIRA, F.; RODRIGUES, R. F. O.; BASTOS, D. H. M.; PEREIRA, F. H. Caracterização morfohistológica e verificação da atividade microbiológica da espécie vegetal Mikania cordifolia (L. f.) Willd. Lecta, v. 18, p. 33-63, 2000.

PAGNI, A. M.; MASINI, A. Morphology, distribution, and histochemistry of secretory structures in vegetative organs of Santolina leucantha Bertol. (Asteraceae). Israel J. Plant Sci., v. 47, p. 257-263, 1999.

RODRIGUES, R. F. O.; OLIVEIRA, F.; KATO, E. T. M. Morfodiagnose da droga conhecida como cipó-almécega - Mikania malacolepsis Robinson. Rev. Farm. Bioquim. USP, v. 32, p. 37-44, 1996.

SASS, J. E. Botanical microtechnique. 2. ed. Ames: Iowa State College Press, 1951. 228 p.

SCHORR, K.; COSTA, F. B. A proposal for chemical characterisation and quality evaluation of botanical raw materials using glandular trichome microsampling of yacón (Polymnia sonchifolia, Asteraceae), an Andean medicinal plant. Braz. J. Pharmacogn., v. 13, p. 1-3, 2003.

SIMMONS, C. B.; KRISHNA-RAJ, S.; SAXENA, P. K. Morphocytological characterization of feverfew, Tanacetum parthenium (L.) Schultz Bip.J. Herbs Spices Med. Plants, v. 9, p. 29-45, 2002.
SOUZA, W. Técnicas básicas de microscopia eletrônica aplicadas às Ciências Biológicas. Rio de Janeiro: Sociedade Brasileira de Microscopia Eletrônica, 1998. $179 \mathrm{p}$.

TERADA, S.; YOSHIMURA, A.; NOGUCHI, N.; ISHIDA, T. Constituents relating to anti-oxidative and alphaglucosidase inhibitory activities in yacon aerial part extract. Yakugaku Zasshi., v. 126, p. 665-669, 2006.

VALENTOVÁ, K.; CVAK, L.; MUCK, A.; ULRICHOVÁ, J.; SIMANEK, V.Antioxidant activity of extracts from the leaves of Smallanthus sonchifolius. Eur. J. Nutr., v. 42, p. 61-66, 2003.

VALENTOVÁ, K.; MONCION, A.; WAZIERS, I.; ULRICHOVÁ, J. The effect of Smallanthus sonchifolius leaf extracts on rat hepatic metabolism. Cell Biol. Toxicol., v. 20, p. 109-120, 2004.

VALENTOVÁ, K.; SERSEN, F.; ULRICHOVÁ, J. Radical scavenging and anti-lipoperoxidative activities of Smallanthus sonchifolius leaf extracts. J. Agric. Food Chem., v. 53, p. 5577-5582, 2005.

VIGNALE, N.D.; GURNI, A. A. Identificación micrográfica de las hojas de Smallanthus sonchifolius (Poepp. \& Endl.) H. Robinson (Asteraceae). Acta Farm. Bonaerense, v. 24, p. 96-98, 2005.

YAN, X.; SUZUKI, M.; OHNISHI-KAMEYAMA, M.; SADA, Y.; NAKANISHI, T.; NAGATA, T. Extraction and identification of antioxidants in the roots of yacon (Smallanthus sonchifolius). J. Agric. Food Chem., v. 47, p. 4711-4713, 1999.

Recebido para publicação em 27 de agosto de 2007 Aceito para publicação em 27 de novembro de 2007 